Original Article - Clinical Science

\title{
Singapore Indian Eye Study 2: methodology and impact of migration on systemic and eye outcomes
}

Charumathi Sabanayagam MD PhD, ${ }^{1,2}$ Wanfen Yip BSc(Hons), ${ }^{1}$ Preeti Gupta PhD, ${ }^{1}$ Riswana BB Mohd Abdul DipSci, ${ }^{1}$ Ecosse Lamoureux PhD, ${ }^{1,3}$ Neelam Kumari PhD, ${ }^{6}$ Gemmy CM Cheung FRCOphth, ${ }^{1,3}$ Carol Y Cheung PhD, ${ }^{4}$ Jie Jin Wang PhD, ${ }^{5}$ Ching-Yu Cheng MD PhD ${ }^{1,3}$ and Tien Yin Wong FRANZCO PhD, ${ }^{1,3}$

1. Singapore Eye Research Institute, Singapore National Eye Centre, Singapore

2. Centre for Quantitative Medicine, Duke-NUS Medical School, Singapore

3. Ophthalmology and Visual Sciences Academic Clinical Program, Duke-NUS Medical School, Singapore

4. Department of Ophthalmology and Visual Sciences, Chinese University of Hong Kong Eye Centre, Hong Kong

5. Centre for Vision Research, University of Sydney, Australia

Correspondence: Dr Charumathi Sabanayagam, Singapore Eye Research Institute, The Academia, 20 College Road Discovery Tower Level 6, Singapore 169856

Email: charumathi.sabanayagam@seri.com.sg

Short running title: SINDI-2 methodology

Received 13 March 2017; accepted 19 April 2017

Conflict of interest: None

Funding sources: This study was supported by the Singapore Ministry of Health's National Medical Research Council (NMRC), NMRC/CIRG/1371/2013, NMRC/STaR/0003/2008 and NMRC/STaR 016/2013.The funding source had no role

This is the author manuscript accepted for publication and has undergone full peer review but has not been through the copyediting, typesetting, pagination and proofreading process, which may lead to differences between this version and the Version of Record. Please cite this article as doi: $10.1111 /$ ceo.12974

This article is protected by copyright. All rights reserved. 
in the design and conduct of the study; collection, management, analysis, and interpretation of the data; preparation, review, or approval of the manuscript; and decision to submit the manuscript for publication.

\section{ABSTRACT}

Importance: Asian Indians are the fastest growing migration groups in the world. Studies evaluating the impact of migration on disease outcomes in this population are rare.

Background: We describe the methodology of the Singapore Indian Eye Study-2 (SINDI-2) aimed to evaluate the impact of migration status on diabetic retinopathy (DR) and other major age-related eye diseases in Asian Indians living in an urban environment.

Design: Population-based cohort study

Participants: 2200 adults who participated in baseline SINDI (2007-09, mean age [range] $=57.8$ [42.7-84.1] years) and SINDI-2 (2013-15, 56.5 [48.4-90.2] years).

Methods: Participants were classified as "first-generation" if they were Indian residents born outside of Singapore and as "second-generation" immigrants (59.7\% in SINDI vs. $63.6 \%$ in SINDI-2) if they were born in Singapore.

Main outcome measures: Response rate, participant characteristics and prevalence of systemic diseases stratified by migration status.

Results: Of the 2914 eligible SINDI participants invited to participate, 2200 participated in SINDI-2 (response rate of 75.2\%). In both SINDI and SINDI-2, compared to first-generation, second-generation immigrants were younger, less likely to have income $<1000$ SGD, had lower levels of pulse pressure, higher levels of high-density lipoprotein cholesterol, had lower prevalence of hypertension, and chronic kidney disease (CKD); had higher prevalence of current smoking, and obesity (all $p<0.05$ ). 
Conclusions and Relevance: In both SINDI and SINDI-2, second-generation immigrants had lower prevalence of cardiovascular risk factors except smoking and obesity compared to first-generation. The final report will confirm if these differences between generations are evident with regards to eye diseases.

Key Words: Asian Indians; association; diabetic retinopathy; incidence; progression;
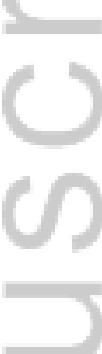

Pro
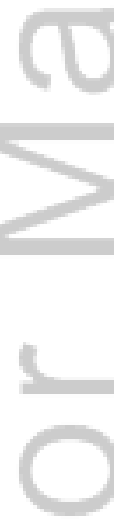

喜

This article is protected by copyright. All rights reserved. 


\section{INTRODUCTION}

Asian Indians make up around one-sixth of the total world population ${ }^{1}$ and India is expected to be the most populous country in the world by $2050 .{ }^{2}$ In parallel, Asian Indians are also among the fastest growing migration groups across Asia and the world. It has been reported that the number of India-born people living outside of India has doubled between 1990 and 2013 from 7 million to 14 million. ${ }^{3}$ Migrant studies have shown that the health risks and health behaviour of migrants tend to be different from the host population influenced by the change in living conditions, environment, lifestyle and physiological and psychological stress associated with migration. ${ }^{4-7}$ For example, a systematic review showed a positive relationship between western acculturation in the host country and obesity in populations migrating from low- or middle-to high-income countries. ${ }^{5}$ In another US study, immigrants residing in the US for $\geq 10$ years had higher prevalence of cardiovascular risk factors including diabetes, hypertension and obesity than those with $<10$ years of residence. ${ }^{4}$ On the other hand, lens opacities were found to be lower in Bangladeshi immigrants in UK compared to Bangladeshis of similar age and gender living in urban and rural Bangladesh ${ }^{6}$ and uncorrected refractive error was found to be associated with low acculturation in the Mexican American immigrants in the US. ${ }^{7}$ Singapore is a major migration destination for Asians, with migrants from China and India. As such, the Singapore population is ideal to study the effects of migration on chronic diseases.

It is well established that the prevalence of diabetes is disproportionately high among Indians; with India alone projected to have the highest number of people with diabetes ( 79.4 million) by $2030 .{ }^{8}$ Consequently, number of people with diabetic retinopathy (DR), a leading cause of preventable blindness is also expected to be higher among Indians compared to other Asian ethnic groups. Besides ethnic 
differences, prevalence of DR has been shown to be heterogeneous varying according to degree of urbanization, and socioeconomic conditions within similar ethnic group. ${ }^{9}$ In India, prevalence of DR has been reported to range from $9.6 \%$ in rural populations ${ }^{10}$ to $37.7 \%$ in urban ${ }^{11}$ populations (Table 1). In Singapore, we reported that one in three Indians had diabetes compared to one in seven Chinese and one in four Malays aged $\geq 40$ years. ${ }^{12}$ Of those with diabetes, DR prevalence was similar in Malays (36.9\%) and Indians (36.5\%) but was lower in Chinese $(30.3 \%)$. Furthermore, we found second generation immigrant Indians (defined as participant born in Singapore with both parents born in India) had higher prevalence of diabetes and DR when compared to first generation (participant as well as both parents born in India) migrant Indians,$^{10}$ highlighting the impact of migration on diabetes and DR. Although several cross-sectional studies have documented the association of migration status with prevalence of diabetes and DR, longitudinal studies evaluating the impact of migration on incidence of diabetes, DR, and other chronic eye diseases, such as cataract, glaucoma, age-related macular degeneration and uncorrected refractive error in Asian populations are rare.

Vision impairment (VI) is a major public health problem in Singapore and worldwide. In Singapore, prevalence of VI including blindness (presenting visual acuity $<20 / 40$ in the better-seeing eye) was found to be $17.5 \%^{13}$ among Indians aged $\geq 40$ years. We recently demonstrated that the burden of VI to be disproportionately high in adults older than $\geq 75$ years compared to adults aged $60-75$ years. ${ }^{14}$ With the ageing of the population, it is important to estimate the incidence, causes and risk factor associations of VI in older populations. The annual cost of VI including direct and indirect costs is estimated to be $\$ 35$ billion in the US ${ }^{15}$ and $\$ 9.8$ billion in Australia. ${ }^{16}$ Among the 42 million blind people and the 217 million with VI globally, more than $60 \%$ live in Asia. Yet, despite the high prevalence, data on economic impact of VI in Asians is lacking, with the exception of one reported study in Japan that shows a 
cost of US $\$ 72.8$ billion. ${ }^{17}$ Measuring the cost of VI and blindness are important for resource allocation, planning of health services, and as a first step in costeffectiveness analyses.

Hence, the primary objective of the SINDI-2 study is to estimate the incidence and progression of DR, VI and major age-related eye diseases, to determine the contribution of traditional cardiovascular (smoking, alcohol consumption, body mass index [BMI], diabetes, hypertension, dyslipidaemia) and novel risk factors (migrant status, kidney function, inflammation and socioeconomic status) to these diseases in Asian Indians, to evaluate the economic impact of VI and to collect a new set of systemic, and ocular measures not available previously. This information will be important to develop evidence-based guidelines for eye screening, health education, risk factor intervention and rehabilitation services. The purpose of this paper is to describe the aims, methodology, response rate and characteristics of SINDI-2 participants. In addition, we also evaluated the association of migration status with systemic outcomes in both visits and with eye outcomes in the baseline visit.

\section{METHODS}

\section{Study design}

The SINDI-2 is a 6-year follow-up study (2013-15) of Indian adults who participated in the baseline SINDI study in 2007-09. The protocol used in SINDI-2 ${ }^{18}$ was similar to that of SINDI baseline study and also the 6-year follow-up of the Singapore Malay Eye Study (SiMES-2). ${ }^{19}$

\section{Study population and recruitment}

Study population consists of eligible Indian adults who participated in the baseline SINDI study conducted from 2007 to $2009 .{ }^{18}$ The recruitment methodology of SINDI 
has been described in detail elsewhere. ${ }^{18}$ Briefly, the sampling frame composed of all Indians aged 40-80 living in designated study areas in the south-western part of Singapore. From a list of 12000 names provided by the Ministry of Home Affairs, an age-stratified random sampling was used to select 6350 names (1201 people of 4049 years, 1809 people of $50-59$ years, 1668 people of $60-69$ years, 1672 people of $70-80$ years). Of the 4168 eligible individuals, 3400 participants took part in the baseline SINDI study (75.6\% response rate). All 3400 participants were sent invitation to attend the 6-year follow-up examinations at the Singapore Eye Research Institute (SERI) via telephone, by mail and/or by home visit. A booklet outlining the overall eye study findings and an invitation letter (reply - paid postage) was sent to all SINDI participants. Participants who did not reply to the invitation letter were contacted by telephone. A person was considered 'ineligible' if he or she is deceased, is terminally ill (e.g. terminal cancer, cognitively impaired, bed-ridden, psychiatric illness), in prison or had migrated. A person was termed 'not contactable' after six unsuccessful telephone calls and home visits. Of the 3400 participants from baseline, 486 participants were found to be ineligible to participate in SINDI-2 examination. Of the 2914 participants who were considered eligible for the follow-up examination, 2200 (75.5\% response rate) participated in SINDI-2 (Figure 1). Overall participation rate of SINDI participants in SINDI-2 was $64.7 \%$ (2200 out of 3400).

In SINDI, 3122 of the 3400 participants ( $91.8 \%$ ) had information on country of birth. In SINDI-2, of the 2200 participants, 1953 (88.8\%) had this information. For the analysis by migration status, we defined 'First-generation' as participants who were born outside of Singapore ( $n=1259$ in SINDI and 711 in SINDI-2) and 'Secondgeneration' as those who were born in Singapore irrespective of the country of birth of their parents ( $n=1863$ in SINDI and 1242 in SINDI-2).

\section{SINDI-2 interview, physical and ophthalmologic examinations}


Participants of SINDI-2 completed an interviewer administered standardized questionnaire and underwent physical, ophthalmic and laboratory examination procedures similar to that have been performed in SINDI. ${ }^{18,} 19$ Interview and laboratory components available in SINDI and SINDI-2 are shown in

Supplementary Table 1. Information on demographic (age, sex), socioeconomic (education, monthly income), life style (smoking and drinking), personal history of diseases, and medication use were obtained from questionnaire. Physical examination included height, weight, body mass index (BMI) and blood pressure (BP) measurements. Ocular examination included refraction, slit-lamp, dilation, fundus photography and optical coherence tomography [OCT] imaging. For laboratory examination, $35 \mathrm{ml}$ of non-fasting venous blood and $20 \mathrm{ml}$ of spot urine sample were collected from each participant. $20 \mathrm{ml}$ of blood samples were sent to Singapore General Hospital laboratory for measurement of blood glucose, HbA1c, lipid profile, and serum creatinine. Kidney function was assessed using estimated glomerular filtration rate (eGFR) from serum creatinine using the CKD-EPI equation. Remaining blood and urine samples were stored at $-80^{\circ} \mathrm{C}$ for future use. The protocol that were different between SINDI and SINDI-2 were 1) in SINDI, all participants underwent subjective refraction; in SINDI-2, only participants with presenting visual acuity of 20/40 or worse underwent subjective refraction, 2) in SINDI, cataract was assessed from both lens photographs graded using Wisconsin Cataract Grading System and Lens Opacity Classification System (LOCS III); in SINDI-2, cataract was assessed based on LOCS III classification only as lens photographs have been shown to be less precise when more than one type of opacity is present compared to slit-lamp examination and have been shown to under estimate posterior subcapsular and cortical cataracts. ${ }^{20}$

\section{Novel components in SINDI-2}


Recent studies conducted in western populations have reported an association between sleep disordered breathing (SDB) and DR, ${ }^{21}$ and glaucoma. ${ }^{22}$ However, this association has not been evaluated in Asians. Therefore, in SINDI-2, a questionnaire module on sleep was introduced which includes duration of sleep, Epworth Sleepiness scale (a measure of daytime sleepiness), the Berlin and STOP-Bang questionnaires (a measure of the risk of obstructive sleep apnoea), the Insomnia Severity Index (a measure of insomnia severity) and other general questions related to sleep-disordered breathing. ${ }^{23-26}$ Second, to quantify healthcare costs associated with the use of inpatient, outpatient, emergency, mental health and complementary and alternative treatments, and lost work time and other indirect costs, a module on 'Healthcare services and expenditure' was introduced. Third, Spectralis-domain optical coherence tomography (SD-OCT, Spectralis, Heidelberg Engineering, Heidelberg, Germany), a state-of-the-art imaging technology was introduced for measuring subclinical retinal and macular disease markers such as choroidal, retinal, peripapillary retinal nerve fiber layer thickness measurements, and optic nerve head assessment.

\section{Quality assurance and control}

Standard operating procedures detailing the methodology of each examination were prepared and read by all staff. To ensure consistency in examination procedures, all staff were trained and were required to demonstrate competency in releavant procedures before being certified to perform procedures for the study. A pilot study $(n=80)$ was also conducted prior to the commencement of the main study to test out recruitment strategies, to examine the work flow of SINDI-2 protocol and to ensure all staff were familiar with the examination procedures.

The quality of the data collected was checked periodically by the key investigators. In certain tests, repeated measurements were performed on the same day to ensure good reliability of data, for example, BP readings were measured twice by a trained 
technician. If the difference in the systolic readings of the 2 recordings was 10 $\mathrm{mmHg}$ or more, or diastolic readings was $5 \mathrm{~mm} \mathrm{Hg}$ or more, the BP check was repeated once more after an interval of 10 minutes. Repeat reading of intraocular presssure (IOP) was also performed if the initial reading was greater than $21 \mathrm{~mm} \mathrm{Hg}$ after an interval of 5 minutes. Similarly, visual field assessments were repeated on the same day if there was glaucomatous visual field defect. ${ }^{27}$ In addition, all study insturments were serviced annually to ensure accuracy in measurements.

Consistency of all examination pocedures were checked throughout the examination period and 6-monthly statistical tests were performed to check for outliers. Data were collected directly using password protected e-CRF via the research electronic data capture software (REDCap). The password protected database was sent to a designated data management team for the implementation of data management procedures including quality checks and cleaning. Retinal photographs were stored in digital format for grading. Images were backed up on to the external drive, and then transferred on to the CD or DVD. This storage method ensures there are 2 sets of copies in different formats. Finally, monthly meetings were conducted between staff and principal investigators to discuss discrepancies that were identified during data collection.

\section{Assessment of risk factors and eye outcomes}

Assessment and definition of systemic risk factors including diabetes, hypertension, obesity, chronic kidney disease (CKD) and cardiovascular disease (CVD) are outlined in Supplementary Table 2. Definitions of the eye conditions and systemic conditions were based on international guidelines and established classification systems. To evaluate the incidence and progression of eye conditions, in particular $A M D$ and $D R$, it was necessary to have gradable retinal photographs at both SINDI and SINDI-2. Assessment and definition of visual outcomes including AMD, DR, cataract, glaucoma and VI are detailed in Supplementary Table 3. 


\section{Impact of eye diseases on QoL and cost}

Longitudinal impact of vision loss on falls, and overall and specific aspects of vision functioning and QoL will be assessed from the VF-9 and IVI questionnaire; economic cost associated with VI will be assessed from the cost expenditure questionnaire.

\section{Statistical Analyses}

In this preliminary report, first, we compared the characteristics of participants who attended SINDI-2 $(n=2200)$ with those who did not $(n=1200)$ using chi square test or ANOVA as appropriate for the variable. Second, we compared the characteristics of the participants stratified by migration status separately for SINDI and SINDI-2. Third, we calculated the prevalence of systemic conditions and compared the prevalence in SINDI and SINDI-2 by migration status. Fourth, we assessed the prevalence of eye diseases and causes of VI in SINDI stratified by migration status.

\section{Analytic plan for the final report}

Once the photos are graded, and eye diagnoses are finalized, we will calculate age standardized 6-year cumulative incidence of DR, and other eye diseases including $A M D$, cataract, glaucoma and VI in the whole population and stratified by migration status. We will use the 2010 Singapore Indian population as the standard population for comparison. We will estimate 6-year progression of eye diseases in those with prevalent disease at baseline. We will use Cox proportional hazards regression models to examine the relationship of risk factors and potential predictors with risk of each of these eye disease using separate models. Generalized estimating equations will be employed to account for the correlations between the two eyes of a single participant. Risk factors associated with progression will be evaluated using separate models. We will use linear regression models to describe associations and determinants of macular thickness, ganglion cell-inner plexiform layer choroidal thickness, RPE elevation (area and volume) and areas of sub-RPE illumination. We 
will use multivariable linear regression models to test the association between major eye diseases and VF and QoL scores after adjusting for potential confounders. For assessing economic cost, a report will be generated to produce a report that presents annual health care utilization and expenditures for all participants. Direct medical expenditures will be stratified by type of service (in total and separately for inpatient, non-inpatient, physician's office (including separate estimates for vision and dental), prescription drug, and non-traditional sources. Indirect costs will be stratified by lost wages due to poor health, the financial value of both formal and informal care giving, and other indirect costs (e.g., transportation costs). For both direct and indirect costs, estimates will be presented separately by key strata, including the presence or absence of a visual impairment. We will also create a person summary file for each respondent that includes a variable indicating the amount of total medical expenditures incurred during the year and separate variables for each expenditure category (i.e., each source of expenditures). The summary file will also include social, cultural, economic, demographic and health status indicators (including visual impairment) at the individual level. Using this dataset, we can then run regression analyses that quantify the incremental cost (for each source of payment) for those with visual impairment after controlling for other confounding variables. All statistical analyses will be performed using the commercially available statistical software STATA statistical software (Version 10, StataCorp, College Station, Texas).

\section{RESULTS}

At baseline, majority of the participants (86\%) were aged $40-70$ years, with $28 \%$ representing age $40-49$ years. In SINDI-2, majority of the participants (76\%) were aged $50-70$ years, with $44 \%$ representing age $50-59$ years. Proportion of participants older than 80 years more than doubled in SINDI-2 compared to SINDI 
( $4.6 \%$ vs. $1.9 \%)$. There was no difference in proportion of participants by gender ( $49.8 \%$ and $50.2 \%$ were female in SINDI and SINDI-2). (Data not shown).

Compared to participants who did not attend SINDI-2, those who attended (Table 2) were younger, less likely to be primary/below educated, having income $<1000$ SGD, current smoker; had lower prevalence of diabetes, hypertension, CVD, and CKD; had lower levels of HbA1c, and systolic BP; had higher levels of BMI and eGFR (all $p<0.05$ ). No significant difference was observed between the two groups with regards to sex, alcohol consumption, diastolic BP, CRP, total, HDL and LDL cholesterol levels.

Table 3 compares the characteristics of participants in SINDI and SINDI-2 by migration status (first vs. second generation). In both SINDI and SINDI-2, compared to first-generation participants, second-generation were younger, less likely to have monthly income $<1000$ SGD, more likely to be current smokers; had lower levels of systolic BP, higher levels of diastolic BP, BMI, eGFR, total, and HDL cholesterol (all $\mathrm{p}<0.05)$. Figure 2 shows the crude prevalence of systemic conditions by migration status in both visits. In both visits, compared to first-generation, second-generation had significantly lower prevalence of hypertension and CKD but higher prevalence of obesity. In addition, at baseline, second-generation had lower prevalence of diabetes and CVD than first-generation immigrants. Figure 3 shows the crude prevalence of eye diseases and Figure 4 shows the causes of VI at baseline SINDI stratified by migration status. Prevalence of major eye diseases including cataract, AMD, glaucoma and VI based on both PVA and BVA were significantly lower in secondgeneration compared to first-generation participants while no difference was observed in the prevalence of $\mathrm{DR}$, and under-corrected refractive error (URE) between the two generations. In both first and second-generation participants, URE was found to be the leading cause of VI followed by cataract although URE 
contributed to a significant proportion in second- compared to first generation $(60.5 \%$ vs. $48.2 \%)$. As diagnoses of some eye conditions in SINDI-2 have not been finalized yet, prevalence of eye conditions in SINDI-2 has not been provided in this report.

\section{DISCUSSION}

SINDI-2 will be the first comprehensive prospective cohort study of eye diseases in Asian Indian immigrants. Information from this prospective study will provide data on the incidence and progression of major age-related diseases, impact of immigration on eye diseases and impact of VI on economic and quality of life amongst Indians in Singapore. The response rate of those who were eligible to participate in SINDI-2 was good (72.5\%).

In the current study, we found that the second-generation immigrants in both SINDI and SINDI-2 had higher prevalence of current smoking, and obesity compared to first-generation immigrants. This finding is consistent with a previous systematic review that reported that the prevalence of obesity in immigrants from low- or middle-income to high-income countries increased with increasing length of residence in the host country. ${ }^{5}$ It is also consistent with another study by Koya et al. ${ }^{28}$ that showed had higher prevalence of obesity, current smoking, and dyslipidemia in earlier immigrants in the US compared to recent immigrants. ${ }^{28}$ Based on our population-based studies, prevalence of current smoking and obesity in Singaporean population of adults aged $40-80$ years (similar to the current study population) were $16 \%$ and $14.3 \%$ (unpublished). Prevalence of current smoking in the second-generation and obesity in the first-generation were similar to that of the Singaporean general population of similar age group. First-generation immigrants had lower prevalence of current-smoking and second-generation immigrants had 
higher prevalence of obesity compared to the Singaporean general population. In the current study, first-generation immigrants had higher prevalence of hypertension and CKD at both visits and diabetes and CVD at baseline contrary to earlier reports. ${ }^{4}$, ${ }^{29}$ The reason for this higher prevalence in first-generation could be speculated due to the older age, lower socioeconomic status as well as psychological stress associated with migration.

Among the eye diseases, we found first-generation immigrants had higher prevalence of cataract, VI, AMD and glaucoma compared to second-generation immigrants at baseline. This could be again due to the older age and higher prevalence of diabetes, hypertension and CVD in the first-generation compared to second-generation immigrants. Among the causes of VI, we found, both first- and second generation had URE as the primary cause followed by cataract. This is consistent with an earlier US report, in which nearly two-thirds of VI among Mexican-American immigrants was contributed by URE. ${ }^{7}$

In a previous report, we reported that the prevalence of diabetes and DR was higher among second-generation compared to first-generation immigrants at SINDI baseline. ${ }^{10}$ However, in the current report, we found the prevalence of diabetes to be higher among first-generation and no significant difference in the prevalence of DR between the two generations at baseline. This difference is contributed by the difference in definition of migration as well as diabetes status. In the previous report, a narrower definition was used to define migration status, i.e. participants born in India or Singapore with both parents born in India were included for defining first-or second generation (1893 of the 3400 were included). Participants who were born outside Singapore but not India (e.g. Pakistan, Srilanka, Bangladesh etc.) and those with one of the parents born in India were excluded. Consequently $44 \%$ of the participants were not included for the analysis. In this current analysis, to take 
advantage of the entire SINDI and SINDI-2 population, we used a broader definition to define the migration status including those who were born outside of India but residing in Singapore under first-generation and second-generation as those born in Singapore irrespective of whether one or both parents born in India. Second, in the previous report, diabetes was defined as a self-reported physician diagnosed diabetes, use of diabetic medication or $\mathrm{HbA} 1 \mathrm{C} \geq 6.5 \%$. In the current analysis, in both SINDI and SINDI-2, we defined diabetes as a self-reported physician diagnosed diabetes, use of diabetic medication or $\mathrm{HbA} 1 \mathrm{C} \geq 6.5 \%$ or random plasma glucose $\geq 200 \mathrm{mg} / \mathrm{dL}$ as per the American Diabetes Association clinical practice recommendations. ${ }^{30}$

SINDI-2 has several novel features. First, although there are several longitudinal eye studies in Western countries, all were conducted at least a decade ago, so that many novel measurements could not be performed at their outset. Our study will provide contemporary data on incidence of eye diseases in Asian Indian immigrants. Second, SINDI-2 will include many state-of-the-art technologies (e.g., SD-OCT) and novel analyses that could shed more light onto the pathogenesis of major eye diseases. Third, SINDI-2 participants are very well characterized at baseline, and we already have a reservoir of baseline data on numerous exposures, laboratory results, and biomarkers. The protocol of SINDI-2 being identical to SiMES- 2 will enable direct comparison, validation, and pooling analyses of the two major Asian ethnic groups. For the first time, cost and economic impact of VI and blindness among Asian Indians will be examined.

The current study has some limitations. Although the response rate of those eligible to participate in SINDI-2 was good (72.5\%), nearly a third of those who attended baseline SINDI were lost-to-follow-up ( $n=3400$ in SINDI and $n=2200$ in SINDI-2). Compared to participants of SINDI-2, nonparticipants $(n=1200)$ at baseline, had 
lower socioeconomic status in terms of education and income, unhealthy lifestyle (higher number of current smokers), worse metabolic profile and higher prevalence of systemic conditions. Although this pattern of differential study participation based on health status is of concern, it is not uncommon in population-based studies, in particular those involving elderly adults. A review on participation rates in epidemiological studies by Galea et al. reported that this pattern of differential study participation based on health status is not uncommon in population-based studies, in particular those involving elderly adults and suggests that decline in participation rate is less likely to have substantial influence in exposure-disease associations or point estimates of outcomes in epidemiological studies. ${ }^{31}$ In line with this report, our finding of a similar pattern of risk factor prevalence by migration status in both visits shows that attrition during follow-up did not result in substantial selection bias over a six-year follow-up of this middle-aged and elderly cohort.

In this preliminary report, we observed first-generation Indian immigrants to have higher prevalence of systemic (hypertension, and CKD in both visits and diabetes and CVD at baseline) and age-related eye diseases at baseline. However, they had low prevalence of lifestyle related risk factors (smoking and obesity) in both visits. The final report will confirm if these differences between generations are evident with regards to incidence of eye diseases. In conclusion, we believe data obtained from SINDI-2 will provide key information on the state of eye health in Asian Indian immigrants that will inform public health strategies for screening, early diagnosis, and intervention in various eye diseases, translatable not only to Singapore Indians but to other migrant Indians living outside India.

\section{ACKNOWLEDGMENTS}

The authors thank the staff and participants in the Singapore Indian Eye Study -2 (SINDI-2) for their important contributions. 


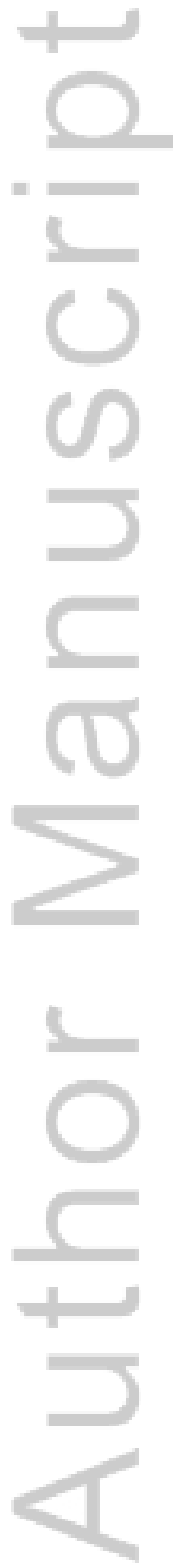

This article is protected by copyright. All rights reserved. 


\section{REFERENCES}

1. Office Of The Director Of Census Operations, B., Patna Census of India: Provisional Population Totals : 2011 See http://munger.bih.nic.in/Data/ppt2011-report1-Bihar.pdf for further details.

2. Ip, G. What India's Growing Population Means for the World Economy as the Number of People in China Shrinks. The Wall Street Journal; 2015 See http://blogs.wsj.com/indiarealtime/2015/11/24/what-indias-growingpopulation-means-for-the-world-economy-as-the-number-of-people-in-chinashrinks/ for further details.

3. C, I. 7 facts about world migration; Pew Research Center See http://www.pewresearch.org/fact-tank/2014/09/02/7-facts-about-worldmigration/ for further details.

4. Commodore-Mensah, Y.; Ukonu, N.; Obisesan, O., et al. Length of Residence in the United States is Associated With a Higher Prevalence of Cardiometabolic Risk Factors in Immigrants: A Contemporary Analysis of the National Health Interview Survey, J Am Heart Assoc. 2016, 5.

5. Delavari, M.; Sonderlund, A. L.; Swinburn, B.; Mellor, D.; Renzaho, A. Acculturation and obesity among migrant populations in high income countries--a systematic review, BMC Public Health. 2013, 13, 458.

6. Finger, R. P.; Sivasubramaniam, S.; Morjaria, P., et al. Migration study of lens opacities in Bangladeshi adults in London and Bangladesh: a pilot study, $\mathrm{Br} \mathrm{J}$ Ophthalmol. 2015, 99, 762-767. 
7. Munoz, B.; West, S. K.; Rodriguez, J., et al. Blindness, visual impairment and the problem of uncorrected refractive error in a Mexican-American population: Proyecto VER, Invest Ophthalmol Vis Sci. 2002, 43, 608-614.

8. Ramachandran, A.; Ma, R. C.; Snehalatha, C. Diabetes in Asia, Lancet. 2010, $375,408-418$.

9. Lee, R.; Wong, T. Y.; Sabanayagam, C. Epidemiology of diabetic retinopathy, diabetic macular edema and related vision loss, Eye Vis (Lond). 2015, 2, 17.

10. Zheng, Y.; Lamoureux, E. L.; Ikram, M. K., et al. Impact of migration and acculturation on prevalence of type 2 diabetes and related eye complications in Indians living in a newly urbanised society, PLoS One. 2012, 7, e34829.

11. Jonas, J. B.; Nangia, V.; Khare, A., et al. Prevalence and associated factors of diabetic retinopathy in rural central India, Diabetes Care. 2013, 36, e69.

12. Huang, O. S.; Tay, W. T.; Ong, P. G., et al. Prevalence and determinants of undiagnosed diabetic retinopathy and vision-threatening retinopathy in a multiethnic Asian cohort: the Singapore Epidemiology of Eye Diseases (SEED) study, Br J Ophthalmol. 2015, 99, 1614-1621.

13. Zheng, Y.; Lavanya, R.; Wu, R., et al. Prevalence and causes of visual impairment and blindness in an urban Indian population: the Singapore Indian Eye Study, Ophthalmology. 2011, 118, 1798-1804.

14. Sabanayagam, C.; Fenwick, E.; Ong, P. G., et al. Visual Impairment in Old and Very Old Community-dwelling Asian Adults, Ophthalmology. 2016, 123, 2436-2438. 
15. Rein, D. B.; Zhang, P.; Wirth, K. E., et al. The economic burden of major adult visual disorders in the United States, Arch Ophthalmol. 2006, 124, 1754-1760.

16. Taylor, H. R.; Pezzullo, M. L.; Keeffe, J. E. The economic impact and cost of visual impairment in Australia, Br J Ophthalmol. 2006, 90, 272-275.

17. Roberts, C. B.; Hiratsuka, Y.; Yamada, M., et al. Economic cost of visual impairment in Japan, Arch Ophthalmol. 2010, 128, 766-771.

18. Lavanya, R.; Jeganathan, V. S.; Zheng, Y., et al. Methodology of the Singapore Indian Chinese Cohort (SICC) eye study: quantifying ethnic variations in the epidemiology of eye diseases in Asians, Ophthalmic Epidemiol. 2009, 16, 325-336.

19. Rosman, M.; Zheng, Y.; Wong, W., et al. Singapore Malay Eye Study: rationale and methodology of 6-year follow-up study (SiMES-2), Clin Exp Ophthalmol. 2012, 40, 557-568.

20. Chew, E. Y.; Kim, J.; Sperduto, R. D., et al. Evaluation of the age-related eye disease study clinical lens grading system AREDS report No. 31, Ophthalmology. 2010, 117, 2112-2119 e2113.

21. Brodie, F. L. How Was Your Sleep? New Implications for Obstructive Sleep Apnea in Retinal Disease, Retina. 2016, 36, 657-659.

22. Liu, S.; Liu, X. Meta-Analysis of Association of Obstructive Sleep Apnea With Glaucoma, J Glaucoma. 2016, DOI 10.1097/IJG.0000000000000526.

23. Bastien, C. H.; Vallieres, A.; Morin, C. M. Validation of the Insomnia Severity Index as an outcome measure for insomnia research, Sleep Med. 2001, 2, 297-307. 
24. Chung, F.; Yegneswaran, B.; Liao, P., et al. STOP questionnaire: a tool to screen patients for obstructive sleep apnea, Anesthesiology. 2008, 108, 812821.

25. Johns, M. W. A new method for measuring daytime sleepiness: the Epworth sleepiness scale, Sleep. 1991, 14, 540-545.

26. Netzer, N. C.; Stoohs, R. A.; Netzer, C. M.; Clark, K.; Strohl, K. P. Using the Berlin Questionnaire to identify patients at risk for the sleep apnea syndrome, Ann Intern Med. 1999, 131, 485-491.

27. Narayanaswamy, A.; Baskaran, M.; Zheng, Y., et al. The prevalence and types of glaucoma in an urban Indian population: the Singapore Indian Eye Study, Invest Ophthalmol Vis Sci. 2013, 54, 4621-4627.

28. Koya, D. L.; Egede, L. E. Association between length of residence and cardiovascular disease risk factors among an ethnically diverse group of United States immigrants, J Gen Intern Med. 2007, 22, 841-846.

29. Teppala, S.; Shankar, A.; Ducatman, A. The association between acculturation and hypertension in a multiethnic sample of US adults, J Am Soc Hypertens. 2010, 4, 236-243.

30. American Diabetes, A. Standards of medical care in diabetes--2012, Diabetes Care. 2012, 35 Suppl 1, S11-63.

31. Galea, S.; Tracy, M. Participation rates in epidemiologic studies, Ann Epidemiol. 2007, 17, 643-653.

32. Raman, R.; Ganesan, S.; Pal, S. S.; Kulothungan, V.; Sharma, T. Prevalence and risk factors for diabetic retinopathy in rural India. Sankara Nethralaya 
Diabetic Retinopathy Epidemiology and Molecular Genetic Study III (SNDREAMS III), report no 2, BMJ Open Diabetes Res Care. 2014, 2, e000005.

33. Namperumalsamy, P.; Kim, R.; Vignesh, T. P., et al. Prevalence and risk factors for diabetic retinopathy: a population-based assessment from Theni District, south India, Br J Ophthalmol. 2009, 93, 429-434.

34. Raman, R.; Rani, P. K.; Reddi Rachepalle, S., et al. Prevalence of diabetic retinopathy in India: Sankara Nethralaya Diabetic Retinopathy Epidemiology and Molecular Genetics Study report 2, Ophthalmology. 2009, 116, 311-318.

35. Rani, P. K.; Raman, R.; Chandrakantan, A.; Pal, S. S.; Perumal, G. M.; Sharma, T. Risk factors for diabetic retinopathy in self-reported rural population with diabetes, J Postgrad Med. 2009, 55, 92-96.

36. Pradeepa, R.; Anitha, B.; Mohan, V.; Ganesan, A.; Rema, M. Risk factors for diabetic retinopathy in a South Indian Type 2 diabetic population--the Chennai Urban Rural Epidemiology Study (CURES) Eye Study 4, Diabet Med. 2008, 25, 536-542.

37. Krishnaiah, S.; Das, T.; Nirmalan, P. K., et al. Risk factors for diabetic retinopathy: Findings from The Andhra Pradesh Eye Disease Study, Clin Ophthalmol. 2007, 1, 475-482.

38. Rema, M.; Premkumar, S.; Anitha, B.; Deepa, R.; Pradeepa, R.; Mohan, V. Prevalence of diabetic retinopathy in urban India: the Chennai Urban Rural Epidemiology Study (CURES) eye study, I, Invest Ophthalmol Vis Sci. 2005, 46, 2328-2333.

39. Narendran, V.; John, R. K.; Raghuram, A.; Ravindran, R. D.; Nirmalan, P. K.; Thulasiraj, R. D. Diabetic retinopathy among self reported diabetics in 
southern India: a population based assessment, Br J Ophthalmol. 2002, 86, 1014-1018.

40. Dandona, L.; Dandona, R.; Naduvilath, T. J.; McCarty, C. A.; Rao, G. N. Population based assessment of diabetic retinopathy in an urban population in southern India, Br J Ophthalmol. 1999, 83, 937-940.

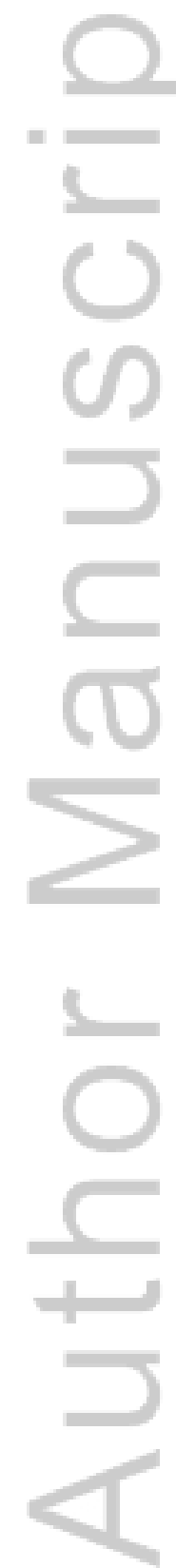

This article is protected by copyright. All rights reserved. 
TABLES

Table 1: Prevalence of DR in population-based studies in Indians in India

\begin{tabular}{|c|c|c|c|c|}
\hline $\begin{array}{l}\text { Author and } \\
\text { publication year }\end{array}$ & Study name and location & Study population & Method of assessment of DR & $\begin{array}{l}\text { Prevalence of DR } \\
(95 \% \mathrm{CI}) \%\end{array}$ \\
\hline Raman R, 201432 & $\begin{array}{l}\text { SN-DREAMS III, Report } 2 . \\
\text { Rural areas of Kanchipuram and Thiruvallur } \\
\text { districts, Tamil Nadu, South India }\end{array}$ & $\begin{array}{l}2730 \text { adults aged } \geq 40 \\
\text { years with diabetes }\end{array}$ & $\begin{array}{l}\text { Four-field stereo colour retinal } \\
\text { photography graded using } \\
\text { modified ETDRS grading system }\end{array}$ & $10.3(8.53-11.97)$ \\
\hline Jonas JB, $2013^{11}$ & $\begin{array}{l}\text { Central India Eye and Medical Study } \\
\text { Rural population in central India }\end{array}$ & $\begin{array}{l}250 \text { adults with } \\
\text { diabetes aged } \geq 30 \\
\text { years }\end{array}$ & $\begin{array}{l}\text { Fundus photographs graded using } \\
\text { the ETDRS grading system. }\end{array}$ & $9.6(4.4-14.8)$ \\
\hline $\begin{array}{l}\text { Namperumalsamy } \\
P, 2009^{33}\end{array}$ & $\begin{array}{l}\text { Theni district, Tamil Nadu, South India } \\
\text { Semi rural population }\end{array}$ & $\begin{array}{l}2802 \text { adults aged } \geq 30 \\
\text { years with diabetes }\end{array}$ & $\begin{array}{l}\text { Direct and indirect } \\
\text { ophthalmoscope }\end{array}$ & $12.2(10.4-14.1)$ \\
\hline Raman R, $2009^{34}$ & $\begin{array}{l}\text { SN-DREAMS, Report } 2 . \\
\text { Urban population, Chennai, South India }\end{array}$ & $\begin{array}{l}1414 \text { adults aged }>40 \\
\text { years with diabetes }\end{array}$ & $\begin{array}{l}\text { Four-field stereo colour retinal } \\
\text { photography graded using } \\
\text { modified ETDRS grading system }\end{array}$ & $18.0(16.0-20.1)$ \\
\hline Rani PK, $2009^{35}$ & $\begin{array}{l}\text { Screening population in three southern rural } \\
\text { districts of Tamilnadu }\end{array}$ & $\begin{array}{l}26,519 \text { adults aged } \\
\geq 30 \text { years with } \\
\text { diabetes }\end{array}$ & Indirect ophthalmoscope & $17.6(17.2-18.1)$ \\
\hline $\begin{array}{l}\text { Pradeepa } \mathrm{R}_{,} \\
2008^{36}\end{array}$ & $\begin{array}{l}\text { CURES EYE Study } 4 \\
\text { Urban population in Chennai, South India }\end{array}$ & $\begin{array}{l}1715 \text { Type } \\
2 \text { diabetic subjects }\end{array}$ & $\begin{array}{l}\text { Four-field stereo colour retinal } \\
\text { photography graded using } \\
\text { modified ETDRS grading system }\end{array}$ & 17.6 \\
\hline $\begin{array}{l}\text { Krishnaiah S, } \\
2007^{37}\end{array}$ & $\begin{array}{l}\text { The Andhra Pradesh Eye Study (APEDS) } \\
\text { Urban (Hyderabad) and three rural districts }\end{array}$ & $\begin{array}{l}201 \text { adults aged } \geq 30 \\
\text { years with diabetes }\end{array}$ & Indirect ophthalmoscope & $\begin{array}{l}19.4(13.9-24.9) \\
\text { Urban vs. rural, }\end{array}$ \\
\hline
\end{tabular}

This article is protected by copyright. All rights reserved. 
Rema M, $2005^{38}$

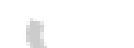

Narendran

$\mathrm{V}, 2002^{39}$

Dandona L, $1999^{40}$

$$
\text { U) }
$$

CURES eye study I

Urban population in Chennai, South India

The Palakkad Eye disease Survey, Palakkad

district, Kerala, South India

Rural and urban population

The APEDS, Urban population in Hyderabad

Andhra Pradesh. 1382 adults aged $\geq 20$
years with diabetes

260 adults aged $\geq 50$ years with diabetes

124 adults aged $\geq 30$

years with diabetes
Four-field stereo colour retinal
photography graded using ETDRS

grading system

Direct and indirect

ophthalmoscope

Indirect ophthalmoscope
$17.6(15.8-19.5)$

$26.8(19.2-4.4)$

Urban $=37.7 \%$

Rural $=22.6 \%$

$22.4 \%$

Abbreviations: CURES, The Chennai Urban Rural Epidemiology Study; ETDRS, Early Treatment of Diabetic Retinopathy Study; SN-DREAMS, Sankara

Nethralaya Diabetic Retinopathy Epidemiology and Molecular Genetic Study;

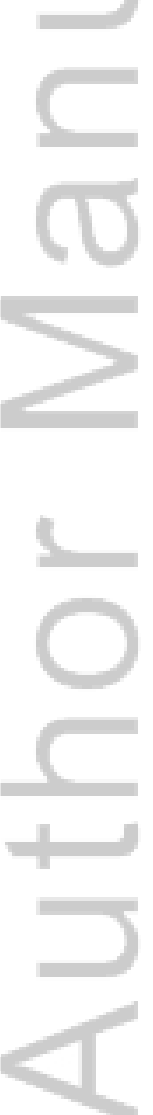

This article is protected by copyright. All rights reserved. 
Table 2: Baseline characteristics of participants who did not attend SINDI-2 compared to those who did

\begin{tabular}{|c|c|c|c|}
\hline Characteristics & Did not return $(n=1200)$ & Returned $(n=2200)$ & $*_{p}$ \\
\hline Age (years) & $60.1(11.1)$ & $56.5(9.2)$ & $<0.001$ \\
\hline Gender, males & 51.6 & 49.4 & 0.2 \\
\hline Education, primary/below, $\%$ & 61.2 & 52.5 & $<0.001$ \\
\hline Monthly income, $<\$ 1000$ & 57.8 & 44.6 & $<0.001$ \\
\hline Current smoking, $\%$ & 17.2 & 13.3 & 0.002 \\
\hline Alcohol consumption, $\%$ & 12.3 & 12.8 & 0.6 \\
\hline Diabetes mellitus, $\%$ & 46.9 & 37.7 & $<0.001$ \\
\hline Hypertension, \% & 63.6 & 53.2 & $<0.001$ \\
\hline $\mathrm{HbA} 1 \mathrm{c}(\%)$ & $6.6(1.5)$ & $6.4(1.3)$ & $<0.001$ \\
\hline Random blood glucose (mmol/L) & $7.5(4.1)$ & $7.0(3.3)$ & $<0.001$ \\
\hline Systolic blood pressure $(\mathrm{mm} \mathrm{Hg})$ & $138.8(21.01)$ & $134.3(19.4)$ & $<0.001$ \\
\hline Diastolic blood pressure $(\mathrm{mm} \mathrm{Hg})$ & $77.5(10.6)$ & $77.7(10.1)$ & 0.5 \\
\hline Body mass index $\left(\mathrm{kg} / \mathrm{m}^{2}\right)$ & $26.1(5.2)$ & $26.2(4.5)$ & 0.005 \\
\hline Total cholesterol $(\mathrm{mmol} / \mathrm{L})$ & $5.2(1.2)$ & $5.2(1.07)$ & 0.3 \\
\hline High-density lipoprotein cholesterol, mmol/L & $1.09(0.3)$ & $1.06(0.3)$ & 0.02 \\
\hline Low-density lipoprotein cholesterol, $\mathrm{mmol} / \mathrm{L}$ & $3.3(1.0)$ & $3.4(0.9)$ & 0.06 \\
\hline History of cardiovascular disease, $\%$ & 17.9 & 12.2 & $<0.001$ \\
\hline Chronic kidney disease, $\%$ & 13.2 & 5.8 & $<0.001$ \\
\hline
\end{tabular}

Data presented are frequency (percentage) or mean (standard deviation) as appropriate for the variable.

*P- value was based on chi-square or $\mathrm{t}$-test as appropriate for the variable.

This article is protected by copyright. All rights reserved. 
Table 3: Characteristics of participants in SINDI 2 stratified by migration status

This article is protected by copyright. All rights reserved. 


\begin{tabular}{|c|c|c|c|c|c|c|}
\hline Characteristics & $\begin{array}{c}\text { First } \\
\text { Generation } \\
(n=1259) \\
\end{array}$ & $\begin{array}{c}\text { Second } \\
\text { Generation } \\
(\mathbf{n = 1 8 6 3 )}\end{array}$ & $\begin{array}{c}\text { P- } \\
\text { value }\end{array}$ & $\begin{array}{l}\text { First Generation } \\
\qquad(\mathbf{n}=711)\end{array}$ & $\begin{array}{l}\text { Second Generation } \\
\qquad(n=1242)\end{array}$ & p* \\
\hline Age (years) & $61.3(10.8)$ & $54.9(8.4)$ & $<0.0001$ & $65.0(10.0)$ & $60.2(7.6)$ & $<0.0001$ \\
\hline Female, $\%$ & 46.9 & 50.2 & 0.08 & 48.4 & 50.5 & 0.4 \\
\hline Education, primary/below, \% & 53.8 & 55.3 & 0.4 & 45.0 & 48.6 & 0.1 \\
\hline Monthly income, <\$1000, \% & 52.6 & 42.7 & $<0.0001$ & 50.5 & 39.6 & $<0.0001$ \\
\hline Current smoking, \% & 10.7 & 17.8 & $<0.0001$ & 7.9 & 15.1 & $<0.0001$ \\
\hline Alcohol consumption, \% & 11.4 & 13.9 & 0.04 & 9.3 & 12.2 & 0.05 \\
\hline $\mathrm{HbA} 1 \mathrm{c}, \%$ & $6.4(1.2)$ & $6.4(1.5)$ & 0.2 & $6.4(1.2)$ & $6.5(1.5)$ & 0.09 \\
\hline Random blood glucose, mmol/L & $7.3(3.5)$ & $7.1(3.6)$ & 0.2 & $7.5(3.4)$ & $7.3(3.6)$ & 0.5 \\
\hline Systolic blood pressure, $\mathrm{mm} \mathrm{Hg}$ & $137.3(20.3)$ & $134.3(19.6)$ & $<0.0001$ & $137.1(18.0)$ & $135.0(18.6)$ & 0.02 \\
\hline Diastolic blood pressure, $\mathrm{mm} \mathrm{Hg}$ & $76.7(10.0)$ & $78.3(10.3)$ & $<0.0001$ & $76.3(9.3)$ & $77.5(9.6)$ & 0.009 \\
\hline Pulse pressure, $\mathrm{mm} \mathrm{Hg}$ & $60.6(17.1)$ & $56.0(15.3)$ & $<0.0001$ & $60.8(15.6)$ & $57.5(14.9)$ & $<0.0001$ \\
\hline Body mass index, $\mathrm{kg} / \mathrm{m}^{2}$ & $25.7(4.5)$ & $26.5(5.0)$ & $<0.0001$ & $26.1(4.3)$ & $26.6(4.7)$ & 0.006 \\
\hline Estimated glomerular filtration rate, $\mathrm{mL} / \mathrm{min} / 1.73 \mathrm{~m}^{2}$ & $83.8(18.8)$ & $89.6(17.4)$ & $<0.0001$ & $82.6(18.2)$ & $87.3(17.0)$ & $<0.0001$ \\
\hline Total cholesterol, mmol/L & $5.04(1.1)$ & $5.3(1.1)$ & $<0.0001$ & $5.0(1.1)$ & $5.3(1.3)$ & $<0.0001$ \\
\hline High-density lipoprotein cholesterol, mmol/L & $1.05(0.3)$ & $1.08(0.3)$ & 0.03 & $1.2(0.3)$ & $1.24(0.3)$ & 0.02 \\
\hline
\end{tabular}

Data presented are frequency (percentage) or mean (standard deviation) as appropriate for the variable.

*P- value was based on chi-square or t-test as appropriate for the variable.

This article is protected by copyright. All rights reserved. 


\section{FIGURES}

Figure 1: SINDI-2 recruitment flowchart

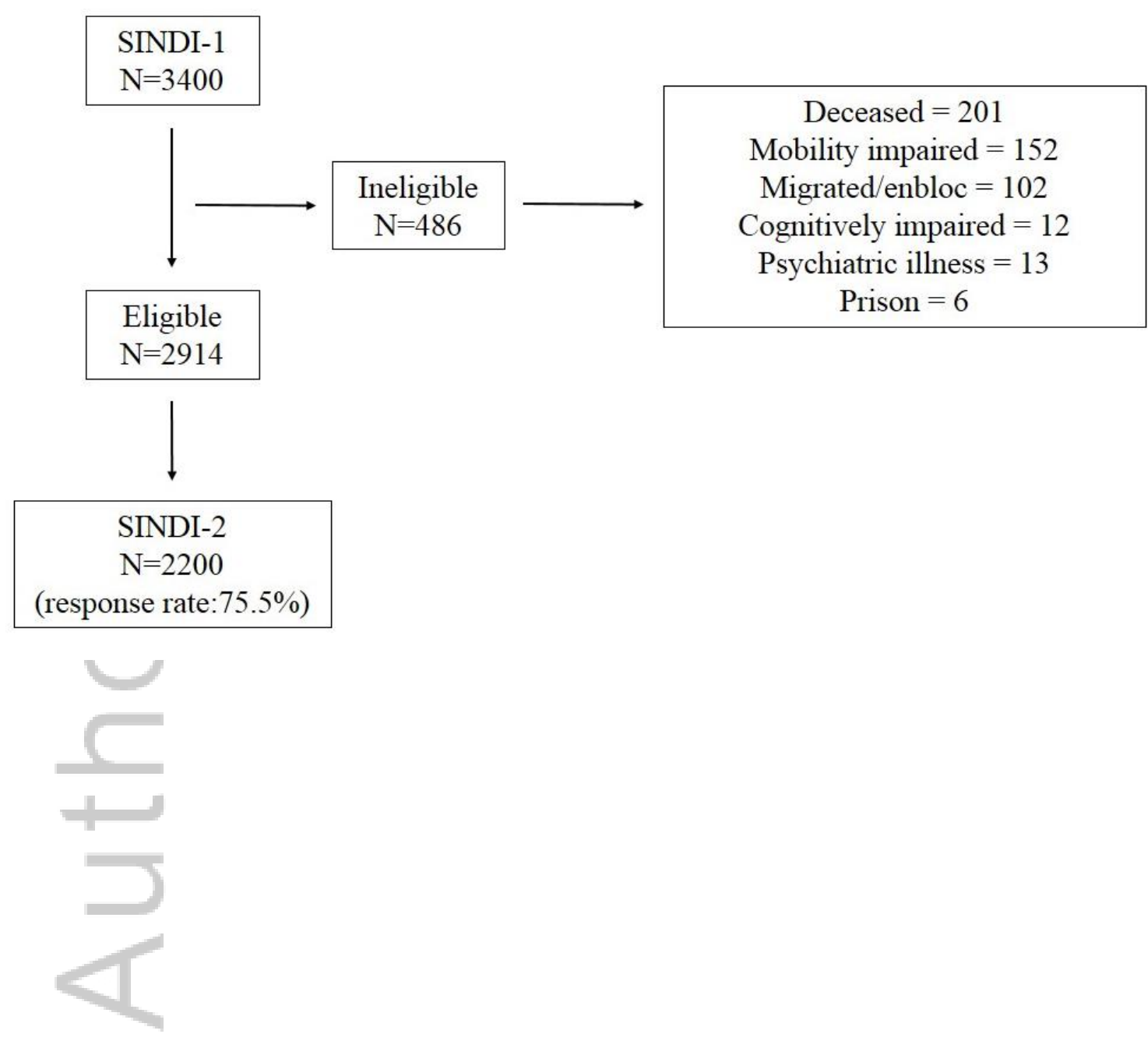

This article is protected by copyright. All rights reserved. 
Figure 2: Prevalence* of systemic conditions in SINDI and SINDI-2
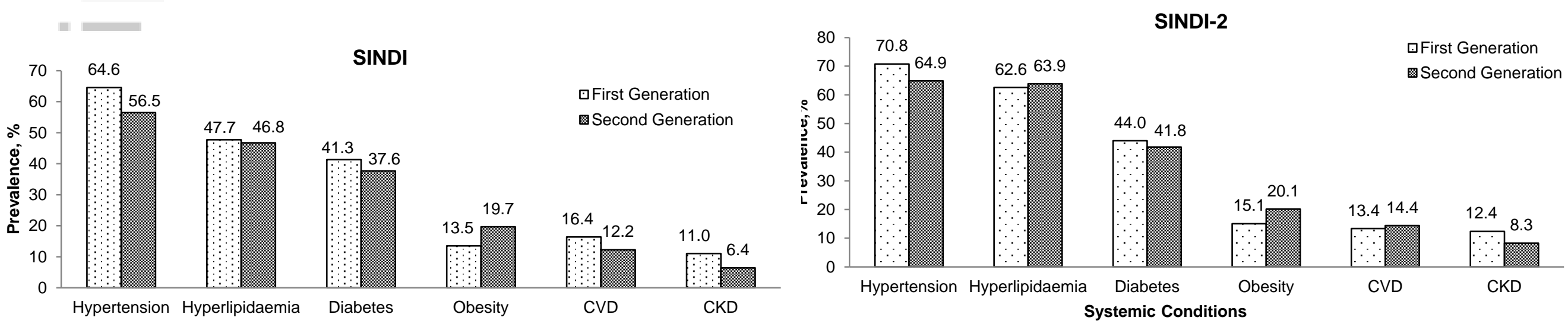

Systemic conditions

* Refers to crude prevalence.

Abbreviations: CKD: chronic kidney disease; CVD: cardiovascular disease;

$\mathrm{p}$ for SINDI : Hypertension $=<0.0001 ;$ Hyperlipidaemia $=0.6 ;$ Diabetes $=0.04 ;$ Obesity $=<0.0001 ; C V D=0.001 ; C K D=<0.0001 ;$ 
p for SINDI 2 : Hypertension $=<0.008 ;$ Hyperlipidaemia $=0.6 ;$ Diabetes $=0.3 ;$ Obesity $=0.005 ; C V D=0.5 ; C K D=0.004 ;$

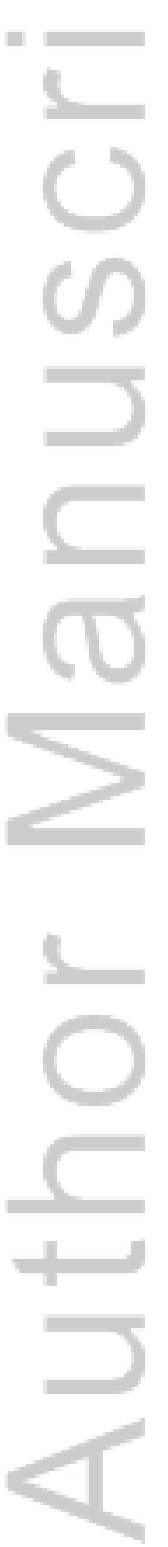

This article is protected by copyright. All rights reserved. 
Figure 3: Prevalence* of eye conditions stratified by migration status at baseline SINDI

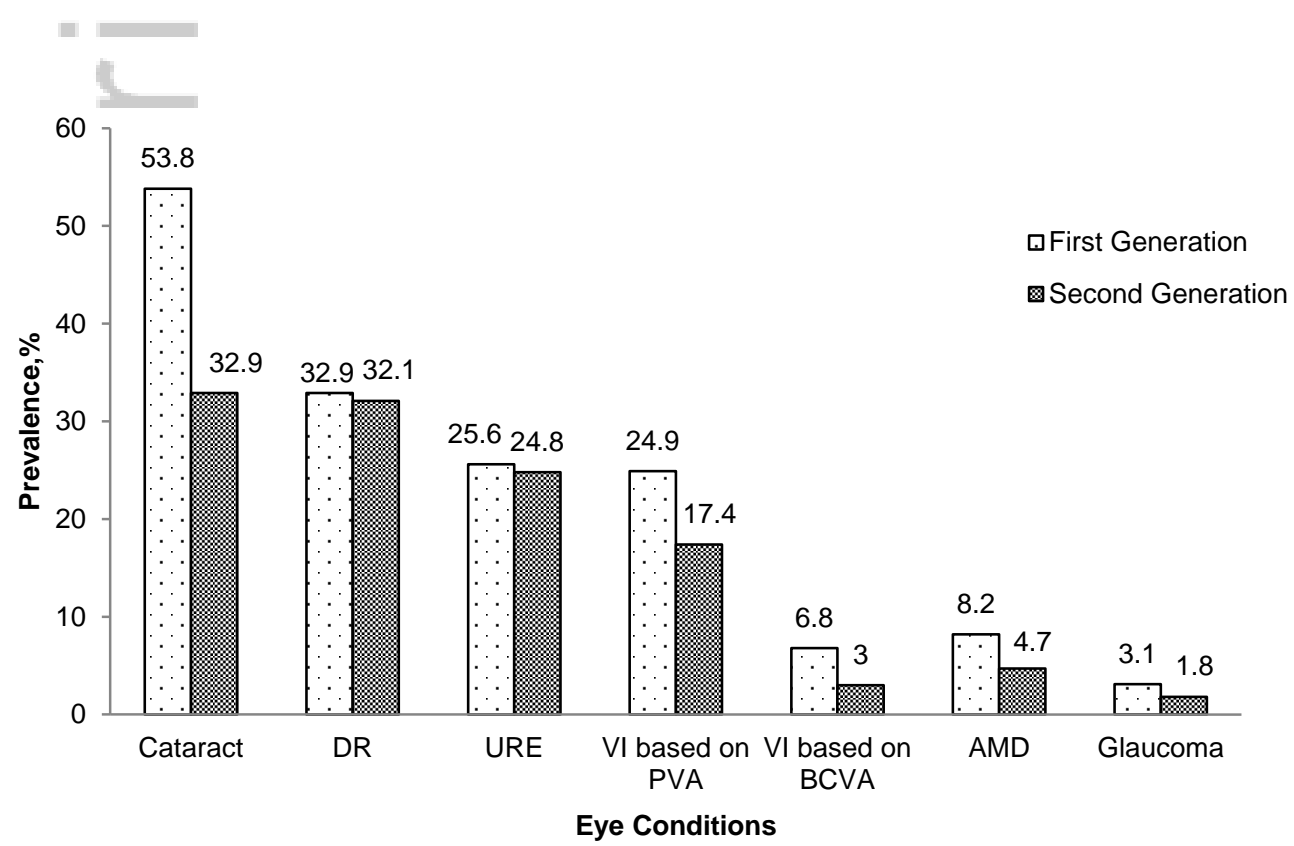

* Refers to crude prevalence.

Abbreviations: DR: diabetic retinopathy; URE: uncorrected refractive errors; VI: visual impairment; PVA: presenting visual acuity; BCVA: best-corrected vision acuity; AMD: age-related macular degeneration; 
Figure 4: Causes of VI defined by presenting visual acuity stratified by migration status at baseline SINDI

\section{First Generation} Others

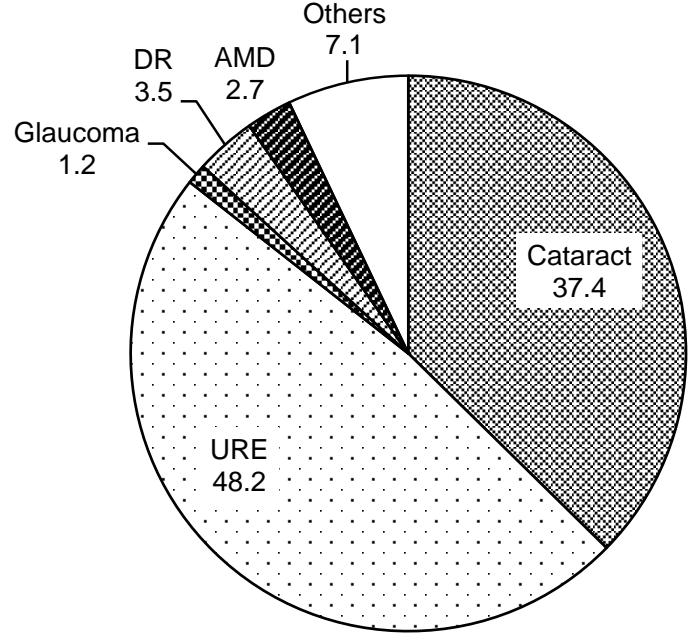

\section{Second Generation}

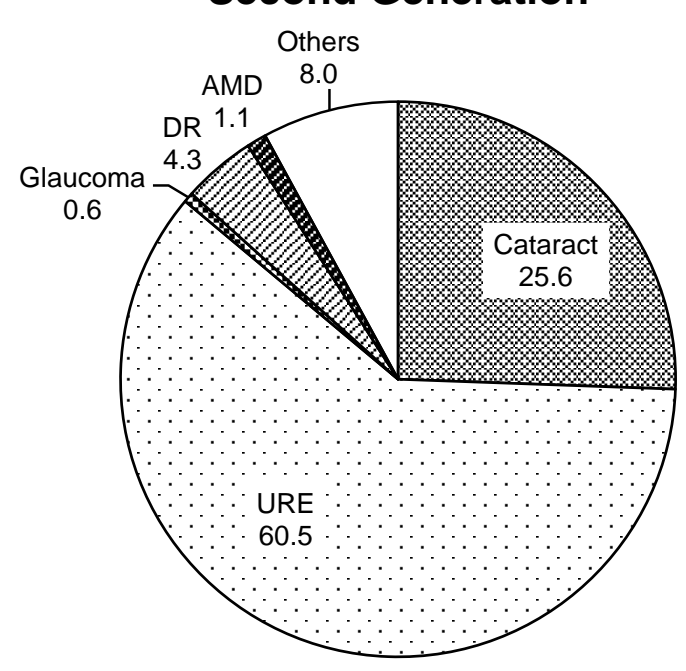

Abbreviations: AMD: age-related macular degeneration; DR: diabetic retinopathy; 


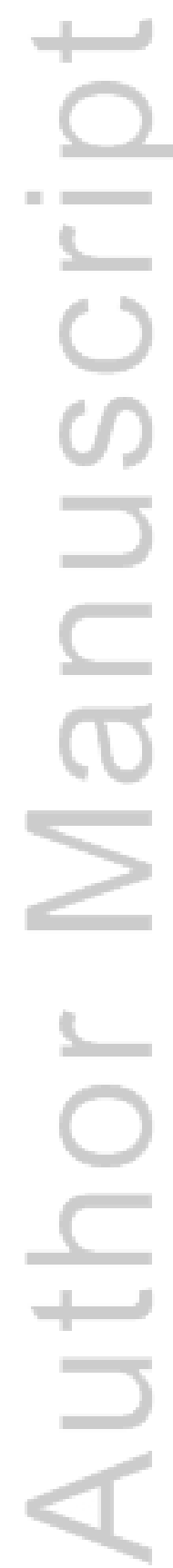

This article is protected by copyright. All rights reserved. 


\section{University Library}

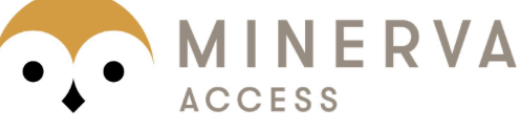

A gateway to Melbourne's research publications

Minerva Access is the Institutional Repository of The University of Melbourne

Author/s:

Sabanayagam, C;Yip, W;Gupta, P;Abdul, RBBM;Lamoureux, E;Kumari, N;Cheung, GCM;Cheung, CY;Wang, JJ;Cheng, C-Y;Wong, TY

Title:

Singapore Indian Eye Study-2: methodology and impact of migration on systemic and eye outcomes

Date:

2017-11-01

Citation:

Sabanayagam, C., Yip, W., Gupta, P., Abdul, R. B. B. M., Lamoureux, E., Kumari, N., Cheung, G. C. M., Cheung, C. Y., Wang, J. J., Cheng, C. -Y. \& Wong, T. Y. (2017).

Singapore Indian Eye Study-2: methodology and impact of migration on systemic and eye outcomes. CLINICAL AND EXPERIMENTAL OPHTHALMOLOGY, 45 (8), pp.779-789. https:// doi.org/10.1111/ceo.12974.

Persistent Link:

http://hdl.handle.net/11343/293039 